\title{
The first year of the Brazilian Journal of Geology
}

Time goes by too fast. A year has already passed since the Brazilian Journal of Geology started circulating with a new name and a new format. This is a very good occasion for an evaluation. How has it been received by its users? How is the process of evaluation of submissions going? What about international visibility?

From our perspective as the people in charge of publication, the result has been positive. The Editorial Council has honored its advisory responsibilities, and its members — including the ones abroad — have satisfactorily performed their mission as associated editors in conducting the process of evaluation. Without a doubt, authors have received good-quality evaluations that will aid them in improving their works.

In this sense, the evaluation process has been rigorous in regards to the content of the submissions, but agile at the same time, as displayed in the boxplots of Figure 1. There is no doubt about the progress in reducing the lenght of time of the evaluation process. For the last issue published - 43(4) — the average of approximately six months is not much different from that of many international journals.

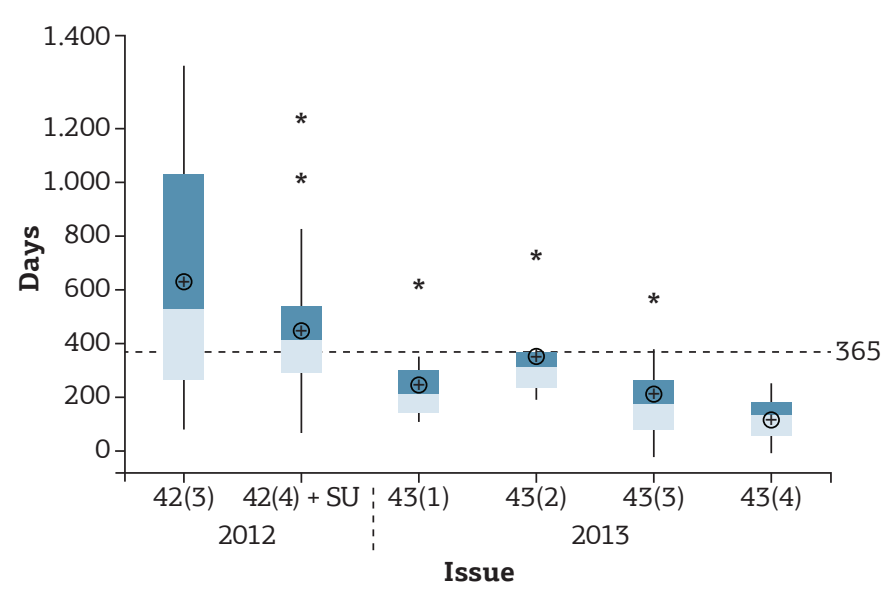

Figure 1. Boxplots showing the evolution of the evaluation process of the BJG in number of days between submission and acceptance for issues between September 2012 and December 2013, that is, from Vol. 42 n. 3 to Vol. 43 n. 4. The vertical limits of the blue boxes englobe the central 50\% of the number of days between submission and acceptance of the articles, and the limit between the dark blue and light blue boxes indicates the median value for the issue.

A very significant and pleasantly surprising result appears in Figure 2, which shows the timeline of daily downloads from the journal's website between June 2012 and December 2013. Up until the end of the first semester of 2013, the daily average of downloads was low, between zero and up to about 3-4 at the most. However, from June 2013 onwards, this number was visibly higher and reached $7-8$ daily downloads, with several peak moments when much larger numbers were achieved. On certain days, more than 20 downloads were requested. What could account for this difference? Could it be something related to improvements in the journal's quality? This factor was possibly important. On the other hand, there is another relevant factor, in our view: the publication of many articles in English reached a broader public outside the country of people obviously interested in our geology. 


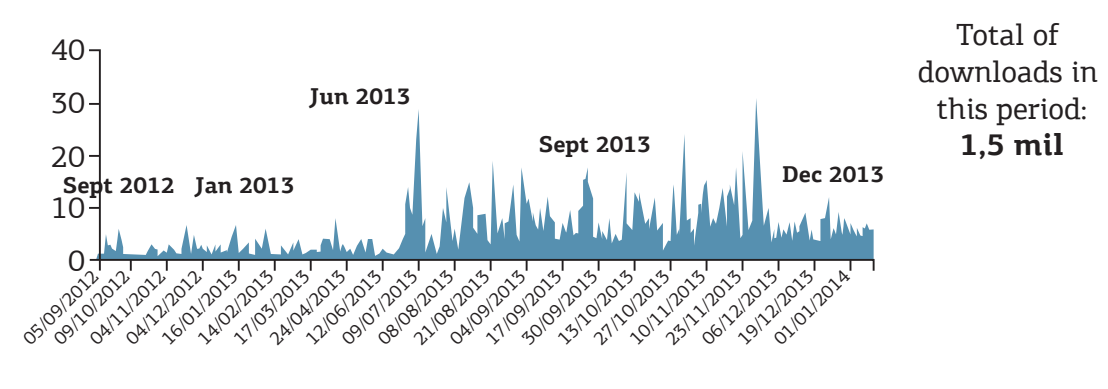

Figure 2. The digital version of the BJG allows open access to the site of the journal. Daily downloads of articles are shown for the period between June 2012 and December 2013.

As we have already emphasized on previous occasions, we believe that the use of the English language in the journal is a preponderant factor to attain greater visibility and will contribute to a larger number of citations of its articles. It seems that this is well understood by BJG users, as nine out of eleven papers in this issue are presented in English. What this reveals is that the BJG will potentially achieve a reasonable impact from its very beginning.

As we have already mentioned, the journal is under observation by SciELO, and we hope to be able to confirm its inclusion in this electronic database soon. We also would like to report that the board of directors of the Brazilian Society of Geology (BSG) has requested Thomson \& Reuters to consider the journal's inclusion in the Web of Science, the main index for international scientific journals.

At the end of 2013, the BSG appointed Prof. Dr. Thomas R. Fairchild, a renowned paleontologist born in the USA, as a member of BJG's Editorial Committee. He is in charge, especially, of devising a structure for the editorial portion of the journal which will aid authors to revise the English version of their papers. Furthermore, the BSG is also considering the pursuit of specific resources for these revisions and possibly for entire translations of papers into English as well.

Finally, complying with a suggestion by SciELO, the BJG inaugurated two sections that were part of the Instructions to Authors but were not being used by BJG authors. The first concerns Rapid communications (papers with about 2,000 words), which merit priority in publication ad the second, Invited reviews, requested by the editors on specific topics of evident interest. These papers, written by renowned geoscientists, may exceed the word limit for regular articles, and undergo special evaluation by the Editorial Committee. On the other hand, we would like to encourage spontaneous submission of review articles by authors of recognized competence, wich, naturally, would receive the same attention as that given to Invited reviews.

The advancements achieved in this first year of the Brazilian Journal of Geology have not only been significant but have also surpassed initial expectations. The response from the Brazilian geoscientific community to the changes in the journal allow us to affirm that the goal of internationalization of the journal is close at hand.

\author{
Umberto Giuseppe Cordani \\ Editor in chief \\ Claudio Riccomini \\ Adjunct editor \\ Thomas Rich Fairchild \\ Editorial Board member
}

